\title{
Designing PISA Like Problems for West Sumatra Mathematics and Science Junior High School Teachers
}

\author{
Ahmad Fauzan ${ }^{\# 1}$, Yuni Ahda ${ }^{\# 1}$, Fridgo Tasman ${ }^{\# 1}$ \\ 1 Jurusan Matematika Universitas Negeri Padang, Padang 25131, Indonesia \\ * Correspondence: fridgo_tasman@fmipa.unp.ac.id
}

Diterima 7 Desember 2019, Disetujui 21 Maret 2020, Dipublikasikan 31 Maret 2020

\begin{abstract}
PISA (Program for International Students Assessment) test result on 2018 put Indonesia in the 72th position of 78 countries. The report showed the importance to improve the level of students thinking ability. There are many possible ways to develop students' thinking. One way to do that is by giving the students drill to solve PISA problems. However, this solution is difficult to implement because designing PISA problems is difficult for the teachers. Therefore, 24 junior high school mathematics and science teachers ware selected in order to give them training and workshop to improve their ability to design PISA like problems using action research methods. Three stages ware implemented in the training and workshop. First, introduction to PISA, Second, designing PISA Problems, and third, trying out and evaluating the test result. Product of the workshop are 48 PISA like problems of mathematics and 42 PISA like problems of science.
\end{abstract}

Keywords — PISA like Problems, Designing PISA like Problems, Junior High School Teacher.

This is an open access article distributed under the Creative Commons 4.0 Attribution License, which permits unrestricted use, distribution, and reproduction in any medium, provided the original work is properly cited. C2017 by author and Universitas Negeri Padang.

\section{Pendahuluan}

PISA (Program for International Students Assessemen) yang dilaksanakan oleh Organization for Economic Cooperation and Development (OECD) setiap tiga tahun sekali dan diumumkan pada tahun berikutnya. PISA fokus pada anak usia 15 tahun (usia dimana siswa menyelesaikan wajib belajar mereka) untuk menggunakan dan memahami pengetahuan matematika mereka untuk menghadapi situasi nyata yang biasa mereka temui.

Negara maju, seperti Jepang, menggunakan hasil PISA untuk menentukan kebijakan pendidikan mereka [1]. Meskipun dari hasil PISA tersebut dalam menimbulkan salah satu kelompok utama yaitu; kelompok pendukung PISA yang menyatakan bahwa hasil PISA dapat digunakan untuk memprediksi pertumbuhan

ekonomi kedepan suatu negara dan
menggambarkan capaian pendidikan suatu
negara.

Hasil PISA Indonesia khususnya untuk bidang matematika masih sangat jauh dari ratarata international. Rata-rata skor Indonesia untuk tes terakhir yang dilaksanakan pada tahun 2015 adalah 386 sedangkan rata-rata skor international adalah 500. Lebih jauh lagi hasil tes terbaru PISA di tahun 2018 menempatkan posisi Indonesia yang berada di peringkat 72 dari 78 negara peserta di bidang matematika dan di peringkat 69 dari 78 negara di bidang sains, hal ini menunjukkan pentingnya untuk meningkatkan kemampuan matematika maupun sains siswa.

[2] menyatakan bahwa PISA dapat membantu Indonesia dalam meningkatkan evaluasi pendidikan dengan bercermin dari hasil PISA kita dapat melakukan refleksi diri dan menyadari bahwa kedepan bangsa ini akan terus tertinggal 
jika tidak dilaksanakan suatu tindakan. Hasil PISA yang rendah juga tercermin dari laporan seorang wartawan senior yang ditulis dalam media daring miliknya indonesiaetc.com yang menyatakan 42 persen siswa Indonesia tidak tahu tentang apapun yang menunjukkan sangat rendahnya kemampuan anak-anak Indonesia. Untuk itu diperlukan upaya akselerasi dari pemerintah dan dukungan seluruh rakyat Indonesia untuk mengejar ketertinggalan ini.

[3], [4], [5] menyatakan salah satu faktor utama penyebab rendahnya hasil capaian pada PISA di Indonesia adalah kualitas guru yang rendah. Hal tersebut diperparah oleh pengetahuan guru yang masih sangat rendah mengenai PISA. Hal tersebut senada dengan [6] yang menyatakan bahwa pengetahuan guru tentang PISA di sumatera barat juga masih sangat rendah. Berdasarkan hasil wawancara dengan guru mata pelajaran matematika yang mengajar di SMP di berbagai daerah di Sumatera Barat, pada umumnya mereka belum mengenal tentang PISA dan sangat membutuhkan pelatihan atau pembinaan tentang PISA itu sendiri.

Berdasarkan hal tersebut maka dirasakan perlu dilaksanakannya peningkatan kemampuan guru matematika dalam merancang soal-soal PISA bagi guru-guru anggota MGMP Matematika Se-Sumatera Barat.

\section{Solusi/Teknologi}

Atas dasar permasalahan yang dihadapi mitra yang dipaparkan pada bagian pendahuluan, beberapa alternatif solusi yang dapat ditawarkan adalah sebagai berikut.

1. Menambah pengetahuan para guru tentang PISA sehingga dapat yang memfasiltasi siswa belajar bermakna (meaningful learning).

2. Menambah wawasan para guru merancang soal-soal PISA sehingga dapat meningkatkan mutu pendidikan matematika di Indonesia umumnya dan di Sumatera Barat khususnya.

\section{Hasil dan Diskusi}

Pretes diberikan kepada para guru peserta kegiatan pada awal kegiatan. Para guru diberikan soal-soal tipe PISA untuk dijawab. Secara garis besar pertanyaan dalam pretes dapat dibagi kedalam tiga bagian yaitu 1) Pengetahuan tentang PISA. 2) Keterampilan Merancang Soal Tipe PISA dan 3) Kemampuan menyelesaikan persoalan tipe PISA.

Hasil pretes menunjukkan bahwa, pada umumnya pengetahuan para guru mengenai PISA masih rendah. Hal ini ditunjukkan hanya $33 \%$ dari para guru yang mengetahui tentang PISA berikut dengan konten-kontennya. Hal inilah yang mungkin menyebabkan kemampuan guru merancang soal tipe PISA juga rendah. Dari hasil pretes hanya $33 \%$ guru mampu merancang soalsoal tipe PISA dengan baik. Akan tetapi kemampuan para guru dalam menyelesaikan persoalan soal tipe PISA sangat baik. Hal ini ditunjukkan dengan $83 \%$ guru dapat menjawab persoalan tipe PISA dengan benar.

Setelah pretes diujikan, para guru peserta kegiatan diberikan pengetahuan tentang PISA matematika dan PISA sains oleh para narasumber yang dapat lihat pada gambar 1 .

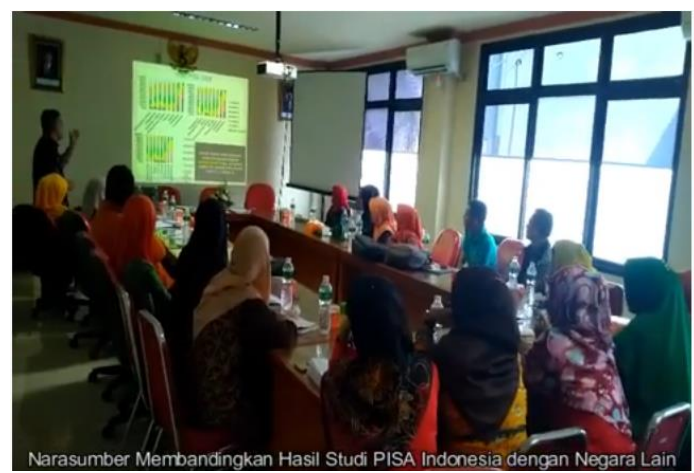

Gambar 1. Penjelasan Nara Sumber Tentang PISA.

Para peserta diberikan penjelasan tentang PISA. Penjelasan tentang PISA meliputi Framework PISA bidang matematika dan Sains.

Untuk framework PISA bidang matematika, nara sumber menjelaskan tentang 4 hal, yaitu, proses matematika pada PISA, konten PISA matematika, Konteks PISA matematiika dan level soal PISA matematika. Terdapat tiga proses matematika yang utama dalam PISA yaitu;

I. Memformulasikan situasi secara matematika

II. Menerapkan konsep, fakta, prosedur, dan penalaran matematika 
III. Menafsirkan, menggunakan, dan mengevaluasi hasil matematika.

Sedangkan untuk konten PISA matematika meliputi

a) Perubahan dan Hubungan (Change and Relationship)

b) Ruang dan Bentuk (Shaped and Space)

c) Kuantitas (Quantity)

d) Ketidakpastian dan Data (Uncertainty and Data.

Selain memiliki konten, soal PISA matematika di implementasikan kedalam konteks yang meliputi ;

I. Konteks Pribadi

II. Konteks Sosial

III. Konteks Pekerjaan

IV. Konteks Ilmiah

Lebih lanjut level soal matematika PISA yang dapat mendeskripsikan pengetahuan peserta didik terbagi menjadi 6 kelompok dengan deskripsi dapat dilihat pada tabel 1 .

\section{Tabel 1. Deskripsi Level PISA Matematika}

\begin{tabular}{|c|c|}
\hline Level & Deskripsi Kompetensi Matematika \\
\hline Level 6 & $\begin{array}{l}\text { Siswa dapat melakukan konseptualisasi } \\
\text { dan generalisasi dengan menggunakan } \\
\text { informasi berdasarkan modelling dan } \\
\text { penelaahan dalam suatu situasi yang } \\
\text { kompleks. Mereka dapat menghubungkan } \\
\text { sumber informasi berbeda dengan fleksibel } \\
\text { dan menerjemahkannya. Pada tingkatan } \\
\text { ini siswa telah mampu berpikir dan } \\
\text { bernalar secara matematika. Mereka dapat } \\
\text { menerapkan pemahamannya secara } \\
\text { mendalam disertai dengan penguasaan } \\
\text { teknis operasi matematika, } \\
\text { mengembangkan strategi dan pendekatan } \\
\text { baru untuk menghadapi situasi baru. } \\
\text { Mereka dapat merumuskan dan } \\
\text { mengkomunikasikan apa yang mereka } \\
\text { temukan. Mereka melakukan penafsiran dan } \\
\text { berargumentasi secara dewasa. }\end{array}$ \\
\hline Level 5 & $\begin{array}{l}\text { Siswa dapat bekerja dengan model untuk } \\
\text { situasi yang kompleks, mengetahui kendala } \\
\text { yang dihadapi,dan melakukan dugaan- } \\
\text { dugaan.Merekadapat } \\
\text { membandingkan, dan mengevaluasi strategi } \\
\text { untuk memecahkan masalah yang rumit } \\
\text { yang berhubungan dengan model ini.Pada } \\
\text { tingkatan ini siswa dapat bekerja dengan } \\
\text { menggunakan pemikiran dan penalaran } \\
\text { yangluas, serta secara tepat } \\
\text { menguhubungkan pengetahuan dan } \\
\text { keterampilan matematikanya dengan }\end{array}$ \\
\hline
\end{tabular}

\begin{tabular}{|c|c|}
\hline & $\begin{array}{l}\text { situasi yang dihadapi. Mereka dapat } \\
\text { melakukan refleksi dari apa yang mereka } \\
\text { kerjakan dan mengkomunikasikannya. }\end{array}$ \\
\hline Level 4 & $\begin{array}{l}\text { Siswa dapat bekerja secara efektif dengan } \\
\text { model dalam situasi yang konkret tetapi } \\
\text { kompleks. Mereka dapat memilih dan } \\
\text { mengintegrasikan representasi yang } \\
\text { berbeda, dan menghubungkan dengan } \\
\text { situasi nyata. Pada tingkatan ini siswa dapat } \\
\text { menggunakan keterampilannya dengan } \\
\text { baik dan mengemukakan alasan dan } \\
\text { pandangan yang fleksibel sesuai dengan } \\
\text { konteks. Mereka dapat memberikan } \\
\text { penjelasan dan mengkomunikasikannya } \\
\text { disertai argumentasi berdasar pada } \\
\text { interpretasi dan tindakan mereka. }\end{array}$ \\
\hline Level 3 & $\begin{array}{l}\text { Siswa dapat melaksanakan prosedur } \\
\text { dengan baik, termasuk prosedur yang } \\
\text { memerlukan keputusan secara berurutan. } \\
\text { Mereka dapat memilih dan menerapkan } \\
\text { strategi memecahkan masalah yang } \\
\text { sederhana. Pada tingkatan ini siswa dapat } \\
\text { menginterpretasikan dan menggunakan } \\
\text { representasi berdasarkan sumber informasi } \\
\text { yang berbeda dan mengemukakan } \\
\text { alasannya. } \\
\text { mengkomunikasikan hasil interpretasi dan } \\
\text { alasan mereka. }\end{array}$ \\
\hline Level 2 & $\begin{array}{l}\text { Siswa dapat menginterpretasikan dan } \\
\text { mengenali situasi dalam konteks yang } \\
\text { memerlukan inferensi langsung. Mereka } \\
\text { dapat memilah informasi yang relevan } \\
\text { dari sumber tunggal dan menggunakan cara } \\
\text { representasi tunggal. Pada tingkatan ini } \\
\text { siswadapat mengerjakan algoritma dasar, } \\
\text { menggunakan rumus, melaksanakan } \\
\text { prosedur atau konvensi sederhana. } \\
\text { Mereka mampu memberikan alasan secara } \\
\text { langsung dan melakukan penafsiran } \\
\text { harafiah. }\end{array}$ \\
\hline Level 1 & $\begin{array}{l}\text { Siswa dapat menjawab pertanyaan yang } \\
\text { konteksnya umum dan dikenal serta semua } \\
\text { informasi yang relevan tersedia dengan } \\
\text { pertanyaan yang jelas. Mereka bisa } \\
\text { mengidentifikasi informasi dan } \\
\text { menyelesaikan prosedur rutin menurut } \\
\text { instruksi yang eksplisit. Mereka dapat } \\
\text { melakukan tindakan sesuai dengan } \\
\text { stimulus yang diberikan. }\end{array}$ \\
\hline
\end{tabular}

Untuk framework PISA bidang sains nara sumber menjelaskan tentang 4 hal, yaitu, kompetensi sains pada PISA, dimensi PISA sains , Konteks PISA sains dan level soal PISA sains. Untuk komptensi sains yang dalam PISA meliputi;

1. Menjelaskan fenomena secara ilmiah 
2. Mengevaluasi dan merancang penyelidikan ilmiah

3. Menafsirkan data dan bukti ilmiah

Sedangkan dimensi PISA sains meliputi

a) Konten

b) Prosedural

c) Epistemik

Selain memiliki kompetensi dan dimensi. soal PISA sains di implementasikan kedalam konteks yang meliputi ;

a) Konteks Kesehatan

b) Konteks Sumber Daya Alam

c) Konteks Kualitas Lingkungan

d) Konteks Bahaya

e) Konteks Sains dan Teknologi

Lebih lanjut level soal PISA sains sendiri terbagi menjadi 6 kelompok dengan deskripsi dapat dilihat pada tabel 2 .

\section{Tabel 2. Deskripsi Level PISA Sains}

\begin{tabular}{|c|c|}
\hline Level & Deskripsi Kompetensi Sains \\
\hline Level 6 & $\begin{array}{l}\text { Peserta didik secara konsisten } \\
\text { mengidentifikasi, menjelaskan, } \\
\text { menerapkan pengetahuan ilmiah dan } \\
\text { pengetahuan tentang sains dalam berbagai } \\
\text { situasi kehidupan yang kompleks. Mereka } \\
\text { dapat menghubungkan berbagai sumber } \\
\text { informasi dan penjelasan serta } \\
\text { menggunakan bukti dari sumber sumber } \\
\text { tersebut untuk membenarkan keputusan. } \\
\text { Mereka secara jelas dan konsisten } \\
\text { menunjukkan pemikiran dan penalaran } \\
\text { ilmuwan, dan mampu menggunakan } \\
\text { pemahaman ilmiah dalammendukung solusi } \\
\text { untuk situasi ilmiah dan teknologi yang } \\
\text { kurang familiar. Peserta didik di tingkat ini } \\
\text { dapat menggunakan pengetahuan ilmiah dan } \\
\text { mengembangkan argument untuk } \\
\text { mendukung keputusan yang berpusat pada } \\
\text { situasi personal, social atau global. }\end{array}$ \\
\hline Level 5 & $\begin{array}{l}\text { Peserta didik dapat mengidentifikasi } \\
\text { komponen ilmiah dari banyak situasi } \\
\text { kehidupan yang komplesk, menerapkan } \\
\text { konsep dan pengetahuan ilmiah tentang } \\
\text { ilmu pengetahuan untuk situasi ini, dan } \\
\text { dapat membandingkan, memilih dan } \\
\text { mengevaluasi bukti ilmiah yang sesuai } \\
\text { untuk menanggapi situasi kehidupan. } \\
\text { Peserta didik pada level ini dapat } \\
\text { menggunakan kemampuan inkuiri yang } \\
\text { dikembangkan dengan } \\
\text { menghubungkan pengetahuan dengan } \\
\text { dengan tepat ke dalam situasi kehidupan. } \\
\text { Mereka dapat membangun penjelasan } \\
\text { berdasarkan bukti dan argumen serta }\end{array}$ \\
\hline
\end{tabular}

\begin{tabular}{|c|c|}
\hline & analisis kritis mereka. \\
\hline Level 4 & $\begin{array}{l}\text { Perserta didik dapat berkerja secara efektif } \\
\text { dengan situasi dan masalah yang mengkin } \\
\text { melibatkan fenomena eksplisit yang } \\
\text { mengharuskan mereka membuat kesimpulan } \\
\text { tentang peran ilmu pengetahuan dan } \\
\text { teknologi. Mereka dapat memilih dan } \\
\text { mngintegrasikan penjelasan dari berbagai } \\
\text { disiplin ilmu atau teknologi dan } \\
\text { menghubungkan penjelasan tersebut secara } \\
\text { langsung dengan aspek situasi kehidupan. } \\
\text { PEserta didik pada level ini dapat } \\
\text { merefleksikan tindakan mereka dan dapat } \\
\text { mengkomunikasikan } \\
\text { menggunakan pengetahuan dan bukti } \\
\text { ilmiah. }\end{array}$ \\
\hline Level 3 & $\begin{array}{l}\text { Peserta didik dapat mengidentifikasi } \\
\text { masalah ilmiah yang dijelaskan dengan jelas } \\
\text { dalam berbagai konteks. Mereka dapat } \\
\text { memilih fakta dan pengetahuan untuk } \\
\text { menjelaskan fenomena dan menreapkan } \\
\text { model sederhana atau strategi penyelidikan. } \\
\text { Peserta didik pada level ini dapat } \\
\text { menafsirkan dan menggunakan konsep } \\
\text { ilmiah dari berbagai disiplin ilmu dan dapat } \\
\text { menerapkannya secara langsung. Mereka } \\
\text { dapat mengembangkan pernyataan singkat } \\
\text { menggunakan fakta dan membuat keputusan } \\
\text { berdasarkan pengetahuan ilmiah. }\end{array}$ \\
\hline Level 2 & $\begin{array}{l}\text { Peserta didik memiliki pengetahuan ilmiah } \\
\text { yang memadai untuk memberikan } \\
\text { penjelasan yang mungkin dalam konteks } \\
\text { yang familiar atau menarik kesimpulan } \\
\text { berdasarkan penyelidikan sederhana. } \\
\text { Mereka mampu mengarahkan penalaran dan } \\
\text { membuat kesimpulan yang benar dari hasil } \\
\text { penyelidikan ilmiah atau pemecahan } \\
\text { masalah. }\end{array}$ \\
\hline Level 1 & $\begin{array}{l}\text { Peserta didik memiliki pengetahuan ilmiah } \\
\text { yang terbatas sehingga hanya dapat } \\
\text { diterapkan pada beberapa situasi yang } \\
\text { familiar. Mereka dapat menyajikan } \\
\text { penjelasan ilmiah yang jelas dari bukti yang } \\
\text { diberikan. }\end{array}$ \\
\hline
\end{tabular}

Setelah nara sumber menjelaskan framework PISA dan memberikan contoh-contoh soal PISA, peserta kegiatan diminta merancang soal-soal tipe PISA. Setelah soal-soal dirancang, para guru diminta mempresentasikannya dan divalidasi bersama. Gambar 2 memperlihatkan proses tersebut.

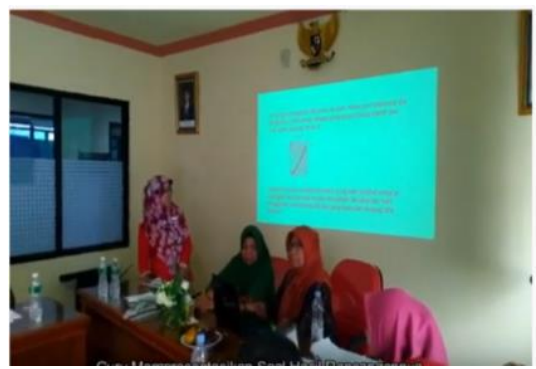


Gambar 2. Proses Validasi Soal Hasil Rancangan

Produk dari kegiatan pengabdian ini adalah 48 soal tipe PISA matematika dan 42 soal tipe PISA sains yang valid. Rekapitulasi soal hasil rancangan para guru peserta kegiatan dapat dilihat pada table 3 dan 4 .

Tabel 3. Rekapitulasi Soal PISA like Matematika Rancancan Guru.

\begin{tabular}{|l|c|c|c|c|c|c|c|c|c|c|c|c|c|}
\hline \multirow{2}{*}{ Konten } & \multicolumn{3}{|c|}{ Proses } & \multicolumn{6}{|c|}{ Level } & \multicolumn{5}{c|}{ Konteks } \\
\cline { 2 - 12 } & I & II & III & 1 & 2 & 3 & 4 & 5 & 6 & I & II & III & IV \\
\hline $\begin{array}{l}\text { Change and } \\
\text { Relasionship }\end{array}$ & 3 & 3 & 5 & - & 1 & 6 & 3 & 1 & - & 7 & - & 4 & - \\
\hline $\begin{array}{l}\text { Space and } \\
\text { Shape }\end{array}$ & 3 & 6 & 5 & - & 5 & 6 & 3 & - & - & 4 & 2 & 7 & 1 \\
\hline Quantity & 4 & 5 & 5 & - & 4 & 6 & 4 & - & - & 4 & 1 & 7 & 2 \\
\hline $\begin{array}{l}\text { Uncertainty } \\
\text { and Data }\end{array}$ & 3 & 4 & 3 & 2 & 1 & 5 & 2 & - & - & 4 & 4 & 1 & 1 \\
\hline
\end{tabular}

Tabel 4. Rekapitulasi Soal PISA like Sains Rancangan Guru.

\begin{tabular}{|c|c|c|c|c|c|c|c|c|c|c|c|c|c|c|}
\hline \multirow{2}{*}{ Dimensi } & \multicolumn{3}{|c|}{ Kompetensi } & \multicolumn{6}{|c|}{ Level } & \multicolumn{5}{|c|}{ Konteks } \\
\hline & I & II & III & 1 & 2 & 3 & 4 & 5 & 6 & 1 & II & III & IV & V \\
\hline Konten & 7 & 1 & 8 & 1 & 5 & 5 & - & 3 & 1 & 2 & - & 1 & - & 12 \\
\hline Prosedural & 4 & 2 & 4 & - & 2 & 5 & 1 & 1 & 1 & - & 1 & 1 & - & 8 \\
\hline Epistemik & 9 & - & 8 & - & 5 & 6 & 3 & 1 & 2 & 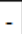 & - & 3 & 1 & 13 \\
\hline
\end{tabular}

Berdasarkan tabel 3, dapat dilihat bahwa para guru matematika tidak ada merancang satu soal dengan level soal 6. Berdasarkan catatan lapangan pengabdian mereka menyatakan bahwa mereka cukup kesulitan merancang soal dengan level 6. Salah satu penyebabnya adalah kegiatan merancang soal untuk level kognitif yang cukup tinggi sangat jarang mereka lakukan. Para guru sudah terbiasa dengan mengambil soal-soal yang telah ada dari buku teks.

Berbeda dengan guru matematika, guru sains dapat merancang soal untuk level 6. Akan tetapi sebaran konteks soal sangat tidak merata, konteks soal yang banyak digunakan adalah konteks sains dan teknologi.

Setelah rancangan soal di buat, para guru dilatih untuk merancang rubrik penskoran untuk persoalan yang telah mereka rancang. Kemudian soal-soal tersebut di cobakan dan di ujikan kepada para siswa mereka di sekolah.

Berikut adalah beberapa contoh soal hasil rancangan para guru matematika.

- Pak Ali seorang peternak kambing. Dia sering mengembalakan kambingnya di daerah padang rumput.

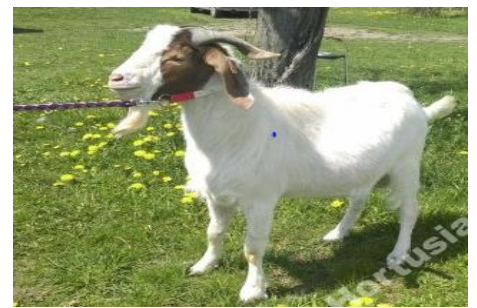

Karena jam istirahat, Pak Ali mengikatkan kambingnya pada sebatang pohon dengan panjang tali 3, 5 meter. Luas maksimal daerah rumput yang dapat dijangkau oleh kambing adalah ...

- Rata-rata berat badan 30 siswa di suatu kelas adalah $48 \mathrm{~kg}$. Jika selisih rata-rata berat badan 5 siswa paling ringan di kelas itu dengan rata-rata berat badan 25 orang lainnya adalah $12 \mathrm{~kg}$, maka ratarata berat badan 5 siswa paling ringan adalah ...

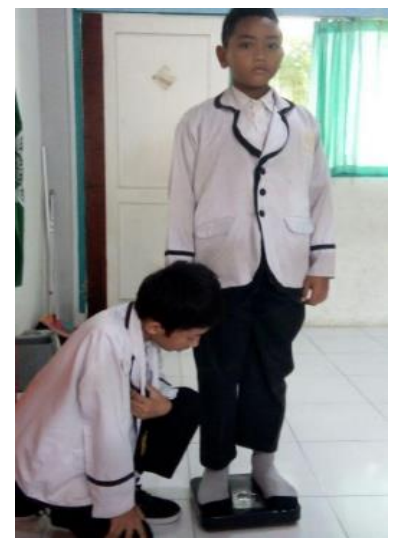

- Pada tanggal 19 september 2019 terjadi pembakaran hutan di dua daerah Riau dan jambi, mengakibatkan terjadinya polusi udara dibeberapa daerah, salah satunya beberapa daerah di provinsi Sumatera barat.dari hasil pantauan ISPU 
diperoleh data kualitas udara kota-kota di sumatera Barat yaitu :

\begin{tabular}{|l|l|l|}
\hline NO & Kabupaten/Kota & Kualitas Udara \\
\hline 1 & Padang & 80 \\
\hline 2 & Solok & 150 \\
\hline 3 & Bukit tinggi & 120 \\
\hline 4 & Darmasraya & 170 \\
\hline 5 & Sijunjung & 120 \\
\hline 6 & Solok selatan & 100 \\
\hline 7 & Padang Panjang & 90 \\
\hline 8 & Pariaman & 70 \\
\hline 9 & Pesisir Selatan & 40 \\
\hline 10 & Payakumbuh & 180 \\
\hline
\end{tabular}

Rata-rata Kualitas udara di Sumatera

Barat adalah ...

Berikut adalah beberapa soal sains tipe PISA hasil rancangan guru.

- Perhatikan Grafik hubungan intensitas cahaya dengan laju foto sintesis berikut ini!

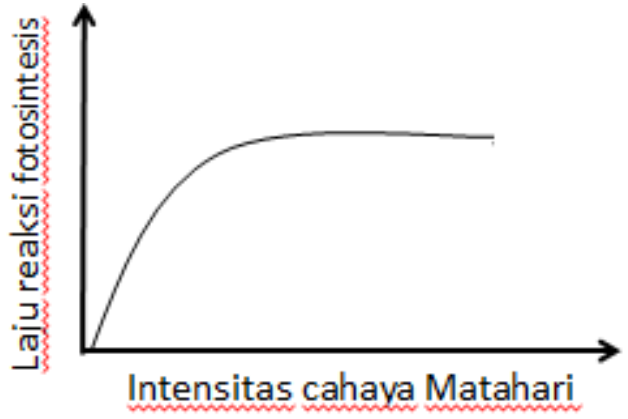

Pertanyaan:

Melihat grafik di atas bagaimana kesimpulan anda tentang hubungan intensitas cahaya dengan laju reaksi fotosintesis?

- Bonus demografis yang dianugerahkan kepada bangsa Indonesia khususnya pada periode 2010-2035 adalah berupa penduduk usia produktif yang jumlahnya cukup besar. Penduduk usia produktif jumlahnya mencapai sekitar $70 \%$ atau mencapai 160 180 juta jiwa pada tahun 2020, sedang yang $30 \%$ nya adalah penduduk yang tidak produktif (usia kurang dari 15 tahun dan usia lebih dari 65 tahun).

Pertanyaan:

Bagaimana dampek keadaan penduduk terhadap ketersediaan lapangan pekerjaan di Indonesia?

- Perhatikan gambar berikut!

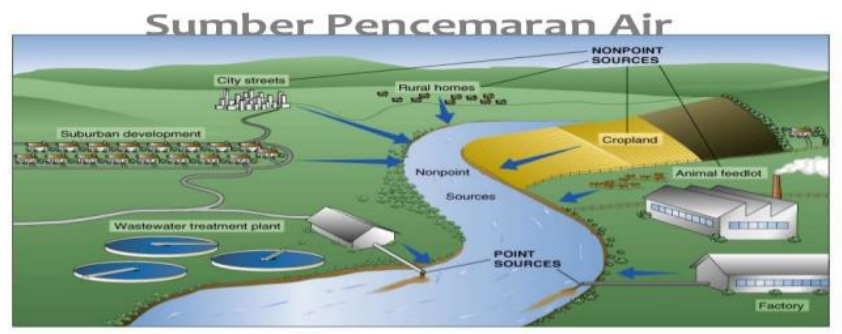

Menurut kamu sumber pencemaran yang paling berbahaya adalah....

Mengapa demikian?

Berdasarkan catatan lapangan kegiatan pelatihan dan workshop di identifikasi bahwa, kesulitan guru dalam merancang soal-soal tipe PISA like disebabkan oleh kurangnya sumber belajar. Para guru mengakui agak kesulitan mencari buku-buku referensi untuk merancang soal-soal tipe PISA. Untuk itu tim pengabdian kepada masyarakat (PKM) menyarankan agar guru dapat merancang soal mereka sendiri seperti yang dilakukan pada pelatihan dan workshop yang diadakan. Selain itu, para guru mengakui bahwa kesulitan dalam merancang soal adalah menentukan level soal dan menjaga sebaran soal, agar setiap konteks dapat di sediakan pada setiap level yang ada. Untuk itu, tim menyarankan agar para guru membiasakan merancang soal mereka sendiri dan membuat bank soal hasil rancangan.

Pada akhir kegiatan para guru memberikan testimoni tentang kegiatan yang di adakan. Para guru merasakan pengetahuan mereka tentang PISA dan kemampuan merancang soal PISA meningkat dengan cukup baik karena penjelasan narasumber kegiatan yang baik tentang bagaimana merancang soal-soal tipe PISA.

\section{Kesimpulan}


Kegiatan program kemitraan masyarakat tentang peningkatan kemampuan guru dalam merancang soal-soal tipe PISA membawa dampak yang cukup signifikan terhadap peningkatan wawasan mitra, yang dalam hal ini adalah guru-guru matematika yang tergabung dalam MGMP Matematika dan Sains SMP Sumatera Barat.

\section{Ucapan Terima Kasih}

Ucapan terima kasih diberikan kepada Universitas Negeri Padang, yang telah mensponsori kegiatan PKM ini melalui skim kegiatan PKM 2019 pendanaan PNBP UNP.

\section{Pustaka}

[1] N. Tasaki, "The impact of OECD-PISA results on Japanese educational policy," Eur. J. Educ., vol. 52, no. 2, pp. 145-153, 2017.

[2] Chamisah, "TIMSS AND PISA-HOW THEY HELP THE IMPROVEMENT OF EDUCATION," Conf. Proc. ARICIS 1, pp. 42-
$56,2017$.

[3] F. Tasman, "IMPROVING PAYAKUMBUH ELEMENTARY TEACHERS' ABILITY IN DESIGNING MATHEMATICAL HIGHER ORDER THINKING SKILLS PROBLEMS," Pelita Eksakta; Vol 2 No 1 Pengabdi. MasyarakatDO - 10.24036/pelitaeksakta/vol2iss 1/61 , Jul. 2019.

[4] A. W. Argina, D. Mitra, N. Ijabah, and R. Setiawan, "INDONESIAN PISA RESULT: WHAT FACTORS AND WHAT SHOULD BE FIXED?," in Proceedings Education and Language International Conference, 2017, vol. 1 , no. 1 .

[5] A. Fauzan, "Analisis Literasi Matematis Siswa SMP di Sumatera Barat.," LP2M Universitas Negeri Padang, Padang, 2012.

[6] A. Fauzan, "Analisis Kemampuan Guru Matematika SMP di kota Padang dalam merancang soal-soal tipe PISA," in Prosiding Seminar Nasional Pembelajaran FISIKA IV, 2017, pp. 52-57. 